\title{
Large adaptive deformable membrane mirror with high actuator density: design and first prototypes
}

\section{Citation for published version (APA):}

Hamelinck, R. F. M. M., Rosielle, P. C. J. N., Steinbuch, M., \& Doelman, N. J. (2005). Large adaptive deformable membrane mirror with high actuator density: design and first prototypes. In 5th International workshop on Adaptive Optics for Industry and Medicine, 29 august-1 september 2005, Beijing, China (pp. 12-). https://doi.org/10.1117/12.669364

DOI:

$10.1117 / 12.669364$

Document status and date:

Published: 01/01/2005

\section{Document Version:}

Accepted manuscript including changes made at the peer-review stage

\section{Please check the document version of this publication:}

- A submitted manuscript is the version of the article upon submission and before peer-review. There can be important differences between the submitted version and the official published version of record. People interested in the research are advised to contact the author for the final version of the publication, or visit the DOI to the publisher's website.

- The final author version and the galley proof are versions of the publication after peer review.

- The final published version features the final layout of the paper including the volume, issue and page numbers.

Link to publication

\section{General rights}

Copyright and moral rights for the publications made accessible in the public portal are retained by the authors and/or other copyright owners and it is a condition of accessing publications that users recognise and abide by the legal requirements associated with these rights.

- Users may download and print one copy of any publication from the public portal for the purpose of private study or research.

- You may not further distribute the material or use it for any profit-making activity or commercial gain

- You may freely distribute the URL identifying the publication in the public portal.

If the publication is distributed under the terms of Article 25fa of the Dutch Copyright Act, indicated by the "Taverne" license above, please follow below link for the End User Agreement:

www.tue.nl/taverne

Take down policy

If you believe that this document breaches copyright please contact us at:

openaccess@tue.nl

providing details and we will investigate your claim. 


\title{
Large adaptive deformable membrane mirror with high actuator density: design and first prototypes
}

\author{
Roger Hamelinck $^{*}{ }^{1}$, Nick Rosielle ${ }^{1}$, Maarten Steinbuch ${ }^{1}$, Niek Doelman $^{2}$ \\ ${ }^{1}$ Technische Universiteit Eindhoven, Department of Mechanical Engineering, Division Dynamical \\ Systems Design (DSD), Den Dolech 2, 5600 MB Eindhoven, The Netherlands \\ ${ }^{2}$ TNO Science and Industry, Opto-Mechanical Instrumentation, \\ Stieltjesweg 1, 2628 CK Delft, The Netherlands
}

\begin{abstract}
A large adaptive deformable mirror with high actuator density is presented. The DM consists of a thin continuous membrane which acts as the correcting element. A grid of low voltage electro-magnetical push-pull actuators, - located in an actuator plate -, impose out-of-plane displacements in the mirror's membrane. To provide a stable and stiff reference plane for the actuators, a mechanically stable and thermally decoupled honeycomb support structure is added. The design is suited for mirrors up to several hundred $\mathrm{mm}$ with an actuator pitch of a few $\mathrm{mm}$.

One of the key elements in the design is the actuator grid. Each actuator consists of a closed magnetic circuit in which a strong permanent magnet (PM) attracts a ferromagnetic core. Movement of this core is provided by a low stiffness elastic guiding. A coil surrounds the PM. Both the coil and the PM are connected to the fixed world. By applying a current through the coil, the magnetic force acting on the core can be influenced. This force variation will lead to translation of the ferromagnetic core. This movement is transferred to the reflective mirror surface in a piston-free manner. The design allows for a long total stroke and a large inter actuator stroke. The actuators are produced in arrays which make the design modular and easily extendable.

The first actuators and an actuator grid are produced and tested in a dedicated test set-up. This paper describes how relevant actuator properties, such as stiffness and efficiency, can be influenced by the design. The power dissipation in the actuator grid is optimized to a few milliwatts per actuator, thereby avoiding active cooling.
\end{abstract}

Keywords: deformable, membrane, mirror, actuator, density, grid, low power

\section{INTRODUCTION}

The application of adaptive optics have widened in the last years. Applications nowadays range from astronomy, laser propagation, ophthalmology and microscopy, to many more fields in industry and medicine. Besides the analogy in the adaptive optics systems, the systems differ both in spatial and temporal characteristics. This can be seen in the number of actuators and control bandwidth. Adaptive optic systems may have limited number of actuators with high control bandwidth or have many actuators with a limited bandwidth.

The traditional market for adaptive optics, astronomy, combines the most challenging requirements, both in spatial resolution and bandwidth. For adaptive optics (AO) applications on existing telescopes as well as future extremely large telescopes (ELT's) the further development of deformable mirror technology is essential. Other adaptive optics applications benefit from this development.

Deformable mirrors are required to have thousands of actuators, to position the mirror surface with nm accuracy and to operate at extremely high bandwidths. This in combination with low total power dissipation and reasonable cost.

*.f.m.m.hamelinck@tue.nl; phone ++31 (0)40 247 4580; fax ++31 (0)40 246 1418; www.wtb.tue.nl 
A design that potentially fulfils these future requirements will be presented. The design, realization and test of this high actuator density mirror is a cooperation of the Technische Universiteit Eindhoven, the opto-mechanical instrumentation department of the Dutch TNO Science and Industry and the Technische Universiteit Delft. In this joint research program the control of large amounts of actuators with high bandwidth is one of the goals.

This paper with outline the principal design and focuses on the design, realization and test of one of the most challenging components in the design: the electromagnetic actuator grid.

\section{THE MIRROR DESIGN REQUIREMENTS}

The actuator spacing in many adaptive optics systems is between 3 and $10 \mathrm{~mm}$. As a starting point in this design the actuator spacing is $6 \mathrm{~mm}$. The arrangement of the actuators (e.g. orthogonal or hexagonal) is free to choose. An extendable design is desired that allows arrays of actuators ranging from several tens up to thousands of actuators. The design furthermore should allow a control bandwidth of at least a few hundred $\mathrm{Hz}$, in order to be applicable in advanced adaptive optics systems. The aim of the mirror is to correct for both low order as well as high order wavefront disturbances, as well as for small errors from misalignment, manufacturing and thermal deformation. The total required minimum stroke is therefore $\pm 10 \mu \mathrm{m}$. The maximum stroke difference between two adjacent actuators is up to $0.4 \mu \mathrm{m}$. To be able to correct wavefront disturbances with sufficient accuracy, the actuator resolution is a few $\mathrm{nm}$. In order to avoid wavefront disturbances introduced by the mirror itself, energy dissipation in heat should be minimized, also to avoid complex cooling systems. The temperature range in which the mirror should function is between $-10^{\circ} \mathrm{C}$ and $30^{\circ} \mathrm{C}$. Furthermore, the mirror should have sufficiently high optical quality.

With requirements like these the deformable mirror can correct an 8-meter visible light wavefront from a telescope up to a Strehl-ratio of 0.85 . Assuming a Fried parameter $r_{0}=0.166 \mathrm{~m}$ (at $\lambda=550 \mathrm{~nm}$ ) and the coherence time $\tau_{0}=40 \mathrm{~ms}$ thereby requiring at least 5000 actuators with $200 \mathrm{~Hz}$ control bandwidth ${ }^{1}$.

\section{DESIGN OVERVIEW}

The design is schematically given in figure 3.1. In the design a few layers can be distinguished. The top layer is a thin membrane, which acts as the correcting element. In the underlying layer - the actuator plate - a grid of electro-magnetical push-pull actuators is located. These actuators are connected with the deformable membrane in a way that no piston- and pinning-effects are visible ${ }^{1}$. The deformable membrane, the membrane-actuator connection and the actuator grid form a thin structure with low out-of-plane stiffness. To provide a stable and stiff reference plane for the actuators a third layer - the support structure - is added. This support structure is a mechanically stable and thermally decoupled honeycomb structure ${ }^{1}$.

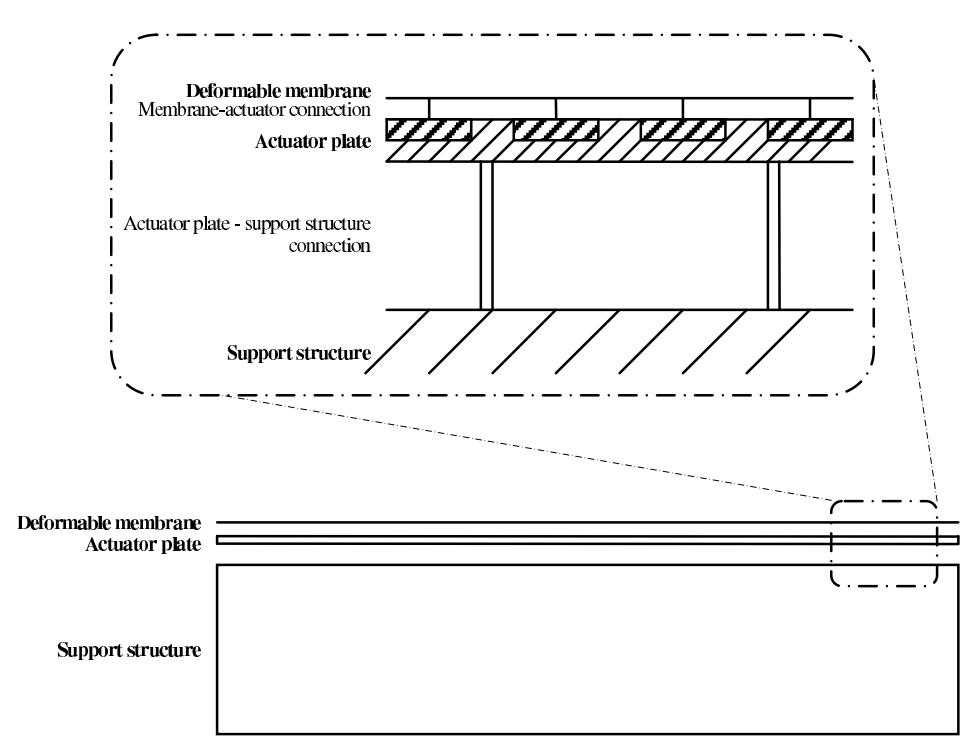

Figure 3.1: Schematic view of the design. 


\section{THE DEFORMABLE MEMBRANE}

4.1 The adaptive deformable membrane

Because of its low mass and low out-of-plane stiffness, a membrane is chosen as the adaptive deformable element. The actuator forces can be kept low, hereby enabling low energy dissipation in heat in the actuators. The actuators impose outof-plane displacements in the membrane. Through this grid of displacements the bending stiffness of the membrane will form a smooth surface.

The thicker this membrane, the more force is needed to deform it. This force will result in energy dissipation in heat in the actuators. To prevent the necessity of active cooling, with its added complexity, it is important to limit the membranes thickness. The lower boundary is set by the maximum allowable quilting $\sigma_{q}$ caused by the gravity acceleration $g$ of the membrane between its support points as formed by the actuators. For a flat plate, an orthogonal actuator grid with spacing $d$, a maximum allowed quilting $\sigma_{q}$, the membrane's density $\rho$, Young's modulus $E$ and Poisson ratio $v$, the minimal required material thickness $h_{\min }$ is given by ${ }^{6}$ :

$h_{\min }=\left(\frac{d}{2 \pi}\right)^{2} \sqrt{\frac{12\left(1-v^{2}\right) \rho g \sqrt{4 \zeta(4) \beta(4)}}{\sigma_{q} E}}$

$\xi$ And $\beta$ are the Riemann-Zeta and Catalan-Beta function and $\zeta(4) \beta(4) \cong 1.07$.

The rms-force necessary to deform the adaptive deformable membrane mirror to correct for atmospheric Kolmogorov turbulence is given $b y^{6}$ :

$\sigma_{f}=\sqrt{10.9} \frac{E h^{3}}{12\left(1-v^{2}\right)} \lambda\left(\frac{r_{0}}{c}\right)^{\frac{-5}{6}} d^{\frac{-7}{6}}$

Where $c$ is the compression factor between the primary mirror and the correcting mirror. For correcting tip/tilt components of the wavefront no extra force is needed since no additional deformation occurs. The deformation forces are one magnitude higher than the inertia forces.

The material properties $\rho$ and $E$ are of great influence on the actuator forces, $\left(\sigma_{f} \sim E h^{3} \sim \rho \sqrt{\rho / E}\right)$ and thereby on the energy dissipation in heat: $\mathrm{P}_{\text {diss }} \sim \sigma_{\mathrm{f}}^{2} \sim \mathrm{E}^{2} \mathrm{~h}^{6} \sim \rho^{3} / \mathrm{E}$. Therefore doubling the membrane's thickness means dissipating a factor 64 more energy in heat.

In table 4.1 for a few materials, their properties, the minimal thickness and rms actuator force are given.

\begin{tabular}{|r|c|c|c|c|c|c|c|c|c|c|}
\hline Material & $\begin{array}{c}\mathrm{E} \\
\cdot 10^{9}\left[\mathrm{~N} / \mathrm{m}^{2}\right]\end{array}$ & $\begin{array}{c}\rho \\
\cdot 10^{3}\left[\mathrm{~kg} / \mathrm{m}^{3}\right]\end{array}$ & $\begin{array}{c}v \\
{[-]}\end{array}$ & $\begin{array}{c}\mathrm{E} / \rho \\
\cdot 10^{6}\left[\mathrm{Nm} / \mathrm{kg}^{3}\right.\end{array}$ & $\begin{array}{c}\left(\rho^{3} / \mathrm{E}\right)^{1 / 2} \\
{\left[\mathrm{~kg}^{3 / 2} / \mathrm{m}^{7 / 2} \mathrm{~N}^{1 / 2}\right]}\end{array}$ & $\begin{array}{c}\rho^{3 /} \mathrm{E} \\
{\left[\mathrm{kg}^{3} / \mathrm{m}^{7} \mathrm{~N}\right]}\end{array}$ & $\begin{array}{c}\mathrm{h}_{\min }[\mu \mathrm{m}] \\
{[\mu}\end{array}$ & $\begin{array}{c}\sigma_{\mathrm{f}} \\
{[\mathrm{N}]}\end{array}$ & $\begin{array}{c}\text { Rel. } \sigma_{\mathrm{f}} \\
{[-]}\end{array}$ & $\begin{array}{c}\text { Rel. } \mathrm{P}_{\text {diss }} \\
{[-]}\end{array}$ \\
\hline Aluminum & 68 & 2.7 & 0.3 & 25.2 & 0.54 & 0.29 & 86 & $1.3 \cdot 10^{-4}$ & 1 & 1 \\
\hline Beryllium & 287 & 1.85 & 0.12 & 155.1 & 0.14 & 0.02 & 37 & $3.6 \cdot 10^{-5}$ & 0.29 & 0.08 \\
\hline ULE & 67 & 2.21 & 0.3 & 30.3 & 0.4 & 0.16 & 93 & $7.8 \cdot 10^{-5}$ & 0.62 & 0.38 \\
\hline Steel & 210 & 7.85 & 0.3 & 26.7 & 1.5 & 2.3 & 83 & $3.5 \cdot 10^{-4}$ & 2.8 & 7.84 \\
\hline $\mathrm{SiC}$ & 420 & 3.1 & 0.16 & 135.5 & 0.26 & 0.07 & 38 & $6.3 \cdot 10^{-5}$ & 0.5 & 0.25 \\
\hline
\end{tabular}

Table 4.1: For different materials the required thickness and $\mathrm{rms}$ actuator forces are given. $\left(\sigma_{\mathrm{q}}=1 \mathrm{~nm}, \mathrm{r}_{0}=0.166 \mathrm{~m}, \lambda=550 \mathrm{~nm}, \mathrm{~d}=6 \mathrm{~mm}\right)$

As the table shows, material choice is of great importance. Besides parameters like force and power dissipation other aspects like availability, manufacturability and optical properties are important. As a starting point beryllium is chosen. 


\subsection{The membrane - actuator connection}

To avoid piston- and pinning-effects in the membrane, only the out-of-plane displacement should be constrained. As seen in figure 4.1, no local tip/tilt should be imposed in the reflective surface. For optimal separation of stiff and non-stiff directions, a thin rod is used (e.g. $50 \mu \mathrm{m})$. If a difference in expansion between the reflective membrane and the actuatorplate occurs, the rods are able to adapt for this difference without introducing surface errors. The rod's bending stiffness should be low relatively to the membranes bending stiffness. With the actuators considered as fixed, the first resonance frequency of the membrane is evaluated with a FEM-analysis. The first resonance frequency for a beryllium membrane $(\mathrm{h}=37 \mu \mathrm{m})$ supported bij an orthogonal grid with actuator spacing $\mathrm{d}=6 \mathrm{~mm}$ is located at $6.3 \mathrm{kHz}$.

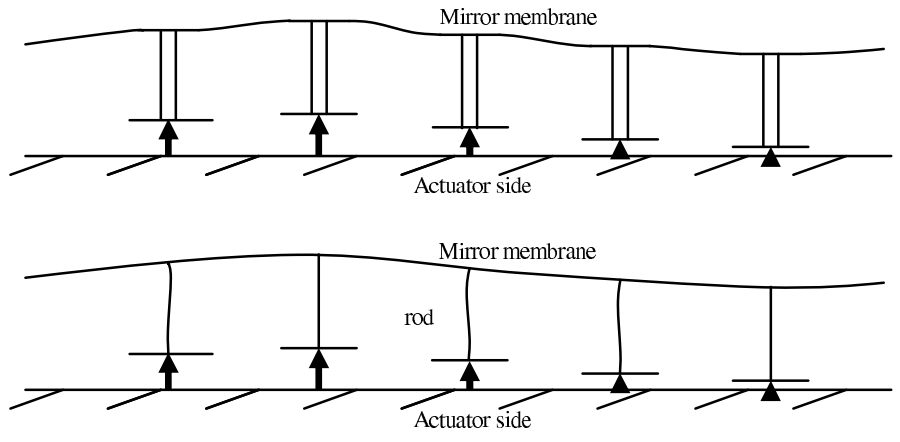

Figure 4.1: Top: Actuator-mirror connection with piston-effects. Under: An actuator-mirror connection free from piston-effect by means of a rod coupling.

\subsection{The actuator requirements}

\section{ACTUATOR GRID}

Because a large number of actuators is needed, it seems attractive to produce these actuators in arrays in a layer based construction instead of producing single actuators and positioning each actuator with respect to its neighbours. For the actuators in the grid a list of main requirements can be made:

- $\quad$ The actuator pitch is $6 \mathrm{~mm}$.

- $\quad$ The minimum stroke is $\pm 10 \mu \mathrm{m}$.

- $\quad$ Control bandwidth $>200 \mathrm{~Hz}$.

- $\quad$ The required rms force is $1 \mathrm{mN}$.

- The resolution is a few $\mathrm{nm}$.

- The design should, aim at minimal energy dissipation.

- $\quad$ The design should be robust and cause no hard points if a single actuator should fail.

- $\quad$ Easy for manufacturing.

With these requirements an actuator grid will be designed. Several types of actuators can be considered:

- Piezo-electrical actuators: they suffer from limited strain, non-linearity, hysteresis, drift and temperature dependent behaviour, and if one actuator fails, a hard point in the mirror surface is created.

- Electro-static actuators: high voltages are needed for the required stroke. There's a strong non-linear relation between voltage and force, and the design is often sensitive for dust particles.

- Electro-magnetic actuators: they can have a high force-density and a linear relation between current and force. A design with low energy dissipation can be made free from mechanical hysteresis, friction and play. If one actuator fails, no hard point occurs in the mirror surface.

Low-voltage electro-magnetic actuators have been designed. The variable reluctance actuator serves as a starting point.

\subsection{The variable reluctance actuator}

Figure 5.1 shows a cross section of three actuators with their connection to the mirror surface and the mirror surface itself. The actuator design consists of a permanent magnet, a surrounding planar coil, an airgap, a base plate and a ferromagnetic membrane as can be seen in figure 5.2.

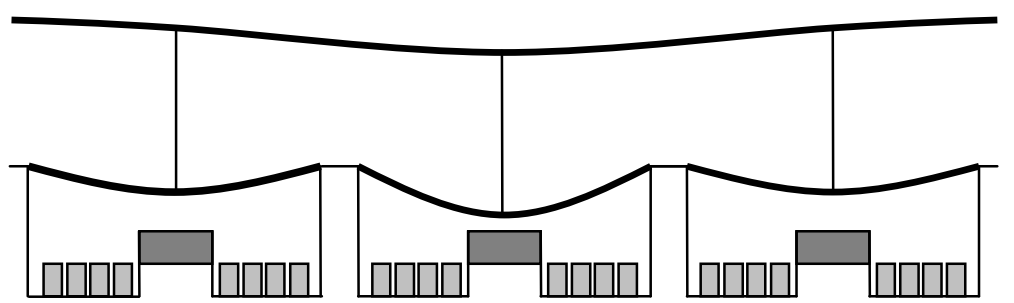

Figure 5.1: Schematic view of the electromagnetic actuators, connection to the mirror and mirror. (Not to scale) 
The magnetic flux will cross the airgap, through the ferromagnetic membrane, the base plate and back to the permanent magnet.

The permanent magnet attracts the ferromagnetic membrane. This gives a static deflection of the membrane. The equilibrium position is determined by the (negative) magnetic force and the (positive) restoring force of the membrane. The magnetic force, and thereby the deflection of the membrane,

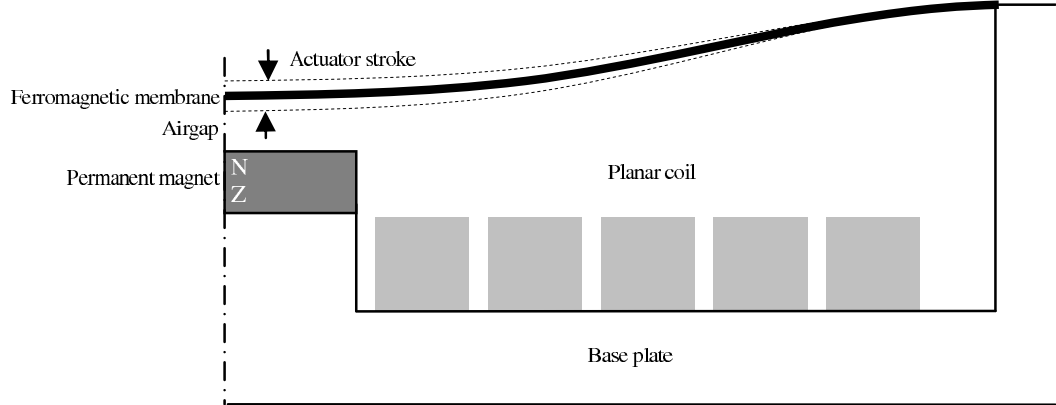

Figure 5.2: Cross section of one actuator.

can be decreased as well as increased by a current through the surrounding coil. This results in a movement of the membrane and provides the actuator with the necessary stroke to impose the mirror's deformation. A very important parameter of the actuator is its stiffness. This is determined by the residue of the (positive) stiffness of the ferromagnetic membrane and the (negative) stiffness of the permanent magnet. It determines the local and global resonance frequencies of the mirror and the force needed for a displacement, and thereby influences the power dissipation.

\subsubsection{Actuator analysis}

\section{The electro-magnetic force}

The electromagnetic force acting on the ferromagnetic core is determined by an electrical equivalent circuit analysis. With Ampere's law for magnetic circuits and Gauss law it is shown that:

$N I=H_{c} l_{c}+H_{m} d_{m}+H_{g} l_{g}$

$H_{c} l_{c}=\frac{B_{c}}{\mu_{c}} l_{c}=\frac{\phi_{c}}{\mu_{c} A_{c}} l_{c}=\phi_{c} R_{c}, H_{g} l_{g}=\frac{B_{g}}{\mu_{0}} l_{g}=\frac{\phi_{g}}{\mu_{0} A_{g}} l_{g}=\phi_{g} R_{g}$

$H_{m} l_{m}=\left(\frac{B_{m}}{\mu_{m}}-H_{c}\right) d_{m}=\frac{\phi_{m}}{\mu_{m} A_{m}} d_{m}-H_{c} d_{m}=\phi_{m} R_{m}-H_{c} d_{m}$

$\phi_{c}=\phi_{g}=\phi_{m}$

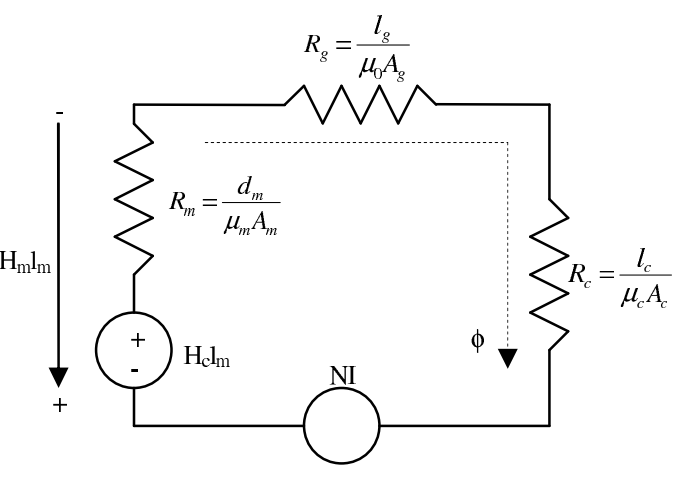

Figure 5.3: The equivalent circuit of the actuator as (5.4) shown in figure 5.2.

In which $N$ is the number of turns in the coil, $I$ is the current through the coil, $H_{c, m, g}$ are the coercive field strengths of the ferromagnetic core, magnet and airgap respectively and $l_{c, g}$ are the lengths through the iron circuit and airgap. $d_{m}$ is the thickness of the magnet, and $\mathrm{A}_{\mathrm{m}}$ is the area of the permanent magnet.

The magnetic force is given by the rate of change of magnetic energy with the airgap height and is given by:

$$
F_{m}=\frac{-\phi^{2}}{2 \mu_{0} A_{m}}=\frac{-1}{2 \mu_{0} A_{m}}\left(\frac{N I+H_{c} d_{m}}{\left(R_{c}+R_{m}+R_{l}\right)}\right)^{2}
$$

\section{The membrane characteristic}

The non-linear spring characteristic of a clamped circular membrane loaded with a central axial force can be approximated by 5 :

$F_{s}=A \frac{E t^{3}}{r^{2}} z+B \frac{E t}{r^{2}} z^{3}$

In which $E$ is the Young's modulus, $t$ is the thickness and $r$ is the radius of the actuator membrane. $z$ is the membranes deflection. The coefficients A and B depend on the boundary conditions of the plate. A linear and a non-linear term can be distinguished, representing the bending stiffness and the stiffness from the in plane stretching of the membrane as it occurs with larger displacements. 


\section{The actuator force, current and power dissipation}

Since stiffness forces are an order of magnitude larger than inertia forces, the force to be produced by the actuator mainly consists of two components:

- $\quad$ A parasitic force $\left(\mathrm{F}_{\mathrm{par}}\right)$, necessary to overcome the actuator's own stiffness $\left(\mathrm{C}_{\mathrm{par}}\right)$,

- The mirror's deformation force $\left(\mathrm{F}_{\text {mir }}\right)$. This is the force necessary to deform the mirror membrane on top of the actuator.

The total actuator force can be written as:

$F_{a c t}=F_{p a r}+F_{m i r}$

$F_{a c t}=C_{p a r} \cdot z_{a c t}+C_{m i r} \cdot z_{m i r}$

Since the wavefront distortion consists of both tip/tilt and higher order components, the actuator stroke $\left(\mathrm{z}_{\mathrm{act}}\right)$ and the mirror surface deformation stroke $\left(\mathrm{z}_{\mathrm{mir}}\right)$ are not the same. (Figure 5.4). In order to correct for the tip/tilt components in the wavefront it is not necessary to deform the mirror's membrane. Only the higher order aberrations will require mirror deformation.

The mirror membrane stiffness $\left(\mathrm{C}_{\mathrm{mir}}\right)$ is position independent, but the parasitic actuator stiffness $\left(\mathrm{C}_{\mathrm{par}}\right)$ is a function of $z_{a c t}$. Both $Z_{a c t}$ and $z_{m i r}$ depend on the statistics of the disturbances.

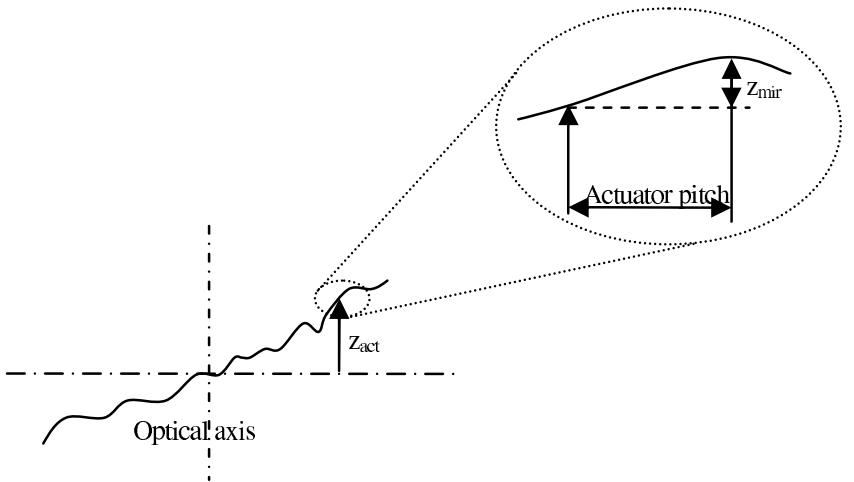

Figure 5.4: Schematic view of the mirror. A distinction between the total actuator stroke and the inter actuator stroke is made.

The rms-value of the total actuator force is given by:

$F_{m s}=\sqrt{\frac{1}{T} \int_{t_{0}}^{t_{0}+T} F_{a c t}^{2}(t) d t}=\sqrt{\frac{1}{T} \int_{t_{0}}^{t_{0}+T}\left(C_{p a r}\left(z_{a c t}(t)\right) \cdot z_{a c t}(t)+C_{m i r} \cdot z_{m i r}(t)\right)^{2} d t}$

To calculate the rms force, the mirror and actuator stiffness and the actuator stroke and inter actuator stroke is needed.

The parasitic actuator stiffness is given by:

$C_{p a r}\left(z_{a c t}\right)=\frac{\partial F_{m}}{\partial z}+\frac{\partial F_{s}}{\partial z}$

The mirror membrane stiffness can be approximated by:

$C_{m i r}=\frac{4 \pi E_{\text {mir }} t_{m i r}^{3}}{3 R_{\text {pitch }}^{2}\left(1-v_{\text {mir }}^{2}\right)}$

In which $E$ and $v$ are the Young's modulus and Poisson ratio of the mirror material, $t$ is the mirror thickness and $R$ represents the inter actuator pitch. $\mathrm{z}_{\mathrm{act}}$ and $\mathrm{z}_{\mathrm{mir}}$ are estimated using a generated set of Kolmogorov wavefronts (e.g. 1000\#) with proper turbulence characteristics $\left(\mathrm{r}_{0}=0.166 \mathrm{~m}, \lambda=550 \mathrm{~nm}, \mathrm{D}_{\text {prim }}=8 \mathrm{~m}\right)$.

Analogue to the rms-force, the rms-current can be calculated:

$I_{m s}=\sqrt{\frac{1}{T} \int_{t_{0}}^{t_{0}+T} I_{a c t}^{2}(t) d t}$

The total actuator current $\left(\mathrm{I}_{\mathrm{act}}\right)$ can be calculated from force equilibrium.

The Ohmic resistance of the coil in the actuator will lead to energy dissipated in heat. This power loss is given by:

$P_{r m s}=\frac{\pi \rho_{e}}{h_{s}}\left(N I_{r m s}\right)^{2}$

Further it is not desired that saturation occurs anywhere in the iron circuit. The ferromagnetic membrane is the most critical element in the iron circuit. The magnetic flux density in the iron circuit can be calculated with:

$B=\frac{\phi}{A} \quad B_{\text {iron }}=\frac{1}{2 \pi t r} \cdot \frac{\left(N I+H_{c} d_{m}\right)}{\left(R_{c}+R_{m}+R_{l}\right)}$ 


\subsubsection{Design with low parasitic forces}

The actuator design driver is low power dissipation which is achieved by minimizing the parasitic forces:

- Force equilibrium in the initial airgap for $\mathrm{I}=0: \quad F_{m}+F_{s}=0$

- Stiffness 'match' between the membrane and magnet: $\frac{\partial F_{m}}{\partial z}+\frac{\partial F_{s}}{\partial z}=C_{p a r}$

If the membrane is considered to be a clamped circular plate with uniform thickness, the stiffness of the membrane is high in comparison to the magnet. To make a better match, a reduction in the membrane's stiffness is needed. This may not lead to a higher flux density in the membrane. Stepped membranes and membranes with continuously decreasing thickness over increasing radius can be used. Figure 5.5 shows results of non linear FEM calculations done with Algor? . Depending on the thickness of the membrane, a reduction in the stiffness up to a factor of two can be obtained. Purpose of the analysis is to find dimensions for the ferromagnetic membrane that give proper characteristics to the actuator. The reluctance of the iron circuit $\left(\mathrm{R}_{\mathrm{c}}=1 \mathrm{e} 6 \mathrm{H}^{-1}\right)$, the magnetic material $\left(\mathrm{H}_{\mathrm{c}}=\right.$ $\left.980000 \mathrm{~A} / \mathrm{m}, \mu_{\mathrm{r}}=1.09\right)$, the initial airgap $(50 \mu \mathrm{m})$, the radius $(\mathrm{r}=2.5 \mathrm{~mm})$ and the Young's modulus of the ferromagnetic membrane $\left(\mathrm{E}=210 \mathrm{e} 9 \mathrm{~N} / \mathrm{m}^{2}\right)$ are fixed. The dimensions of the magnet (radius and thickness) are varied between $0.25-0.75 \mathrm{~mm}$. A parameter search for the initial deflection and thickness of the membrane at $\mathrm{r}=0$ is performed for different values of $\mathrm{C}_{\mathrm{act}}$.

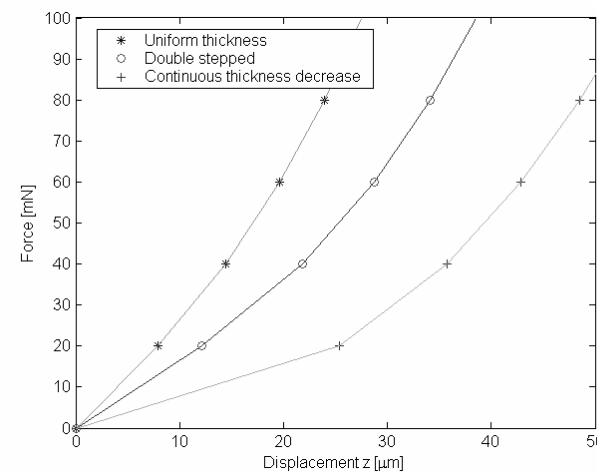

Figure 5.5: The non-linear stiffness of different clamped circular membranes. $(\mathrm{t}=40 \mu \mathrm{m}$ at $\mathrm{r}=0)$

The initial deflection and membrane thickness are the only two unknown parameters in equation (5.15) and (5.16). The solution found is checked for magnetic saturation.

The analysis shows that no practical solution can be found with desirable low stiffness $\left(\mathrm{C}_{\mathrm{act}} \approx 1000 \mathrm{~N} / \mathrm{m}\right)$. It can be concluded that in order to avoid saturation a certain area for the flux to pass through is necessary. This area will contribute to undesirably high actuator stiffness. A solution is found in a design where the flux circuit is decoupled from the parts that determine the stiffness of the actuator.

\section{THE IMPROVED VARIABLE RELUCTANCE ACTUATOR}

It appeared difficult to make an actuator design with the desired mechanical characteristics that avoids magnetic saturation in the ferromagnetic membrane. This problem is solved by separation of the magnetic flux circuit and the parts that determine the mechanical stiffness, as is shown in the design of figure 6.1 .

The design consists of a permanent magnet (1), a surrounding coil (2), an airgap (3), a ferromagnetic moving core (4), a membrane suspension (5), a second airgap (6), and a base plate (7). The magnetic flux crosses the first airgap, through the ferromagnetic core, crosses the second airgap to the pole shoes (8) and returns via the base plate back to the other pole of the permanent magnet. The attraction force of the permanent magnet gives a static deflection of the ferromagnetic core suspension. The current through the coil will either decrease or increase this deflection.

As in the previous design a match is made between a positive spring and a negative spring. However there is no longer any severe coupling between them. A patent is pending for the new design.
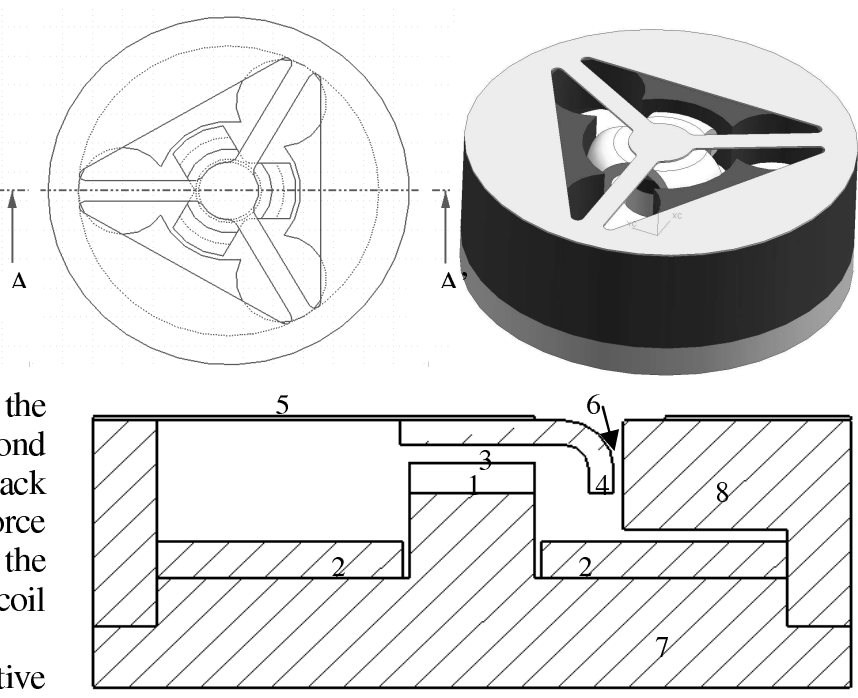

Section A-A'

Figure 6.1: The improved variable reluctance actuator. 


\subsection{The electromagnetic force characteristic}

To calculate the electromagnetic force acting on the ferromagnetic core an electrical equivalent circuit analysis is made. The circuit is shown in figure 6.2. Because an extra airgap is introduced, an additional reluctance term arises, which is a parallel connection of three reluctances. The force acting on the core is now given by:

$$
F_{m}=\frac{-1}{2 \mu_{0} A_{m}}\left(\frac{H_{c} d_{m}+N I}{R_{m}+R_{g 1}+R_{c}+R_{g 2}+R_{b}}\right)^{2}
$$

In which:

$$
\begin{aligned}
& R_{m}=\frac{d_{m}}{\mu_{r} A_{m}}, \quad R_{g 1}=\frac{l_{g 1}}{\mu_{0} A_{m}}, \\
& R_{g 2}=\frac{l_{g 2}}{3 \mu_{0} A_{g 2}}, \quad R_{c}=\frac{l_{c}}{\mu_{c} A_{c}}, \quad R_{b}=\frac{l_{b}}{\mu_{b} A_{b}}
\end{aligned}
$$

The reluctance of the second airgap is constant over the stroke and kept relatively small because of the large area for the flux to pass through.

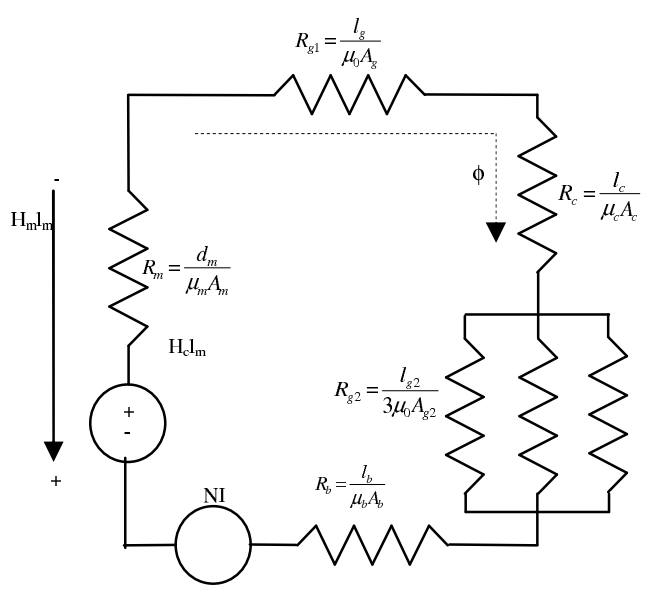

Figure 6.2: The electrical equivalent circuit of the actuator as shown above.

\subsection{Actuator performance}

An actuator analysis is made with a $\mathrm{SmCo}_{5}$ permanent magnet $(\varnothing 1 \times 0.25 \mathrm{~mm})$, a copper coil and a $75 \mu \mathrm{m}$ airgap. The suspension is made from a $30 \mu \mathrm{m}$ thick titanium foil. The following figures are obtained.

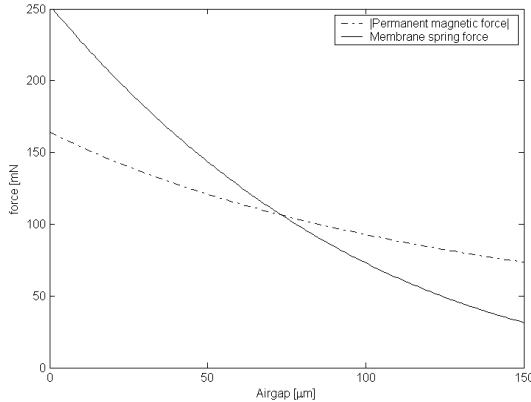

Figure 6.3: The permanent magnetic force and the spring force as function of the airgap. The equilibrium is at $75 \mu \mathrm{m}$.

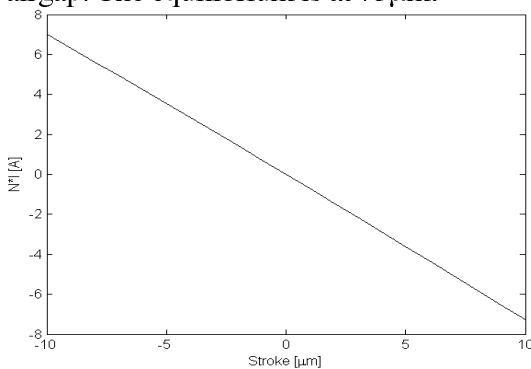

Figure 6.6: The number of Ampère-turns needed to translate the ferromagnetic core around the equilibrium position.

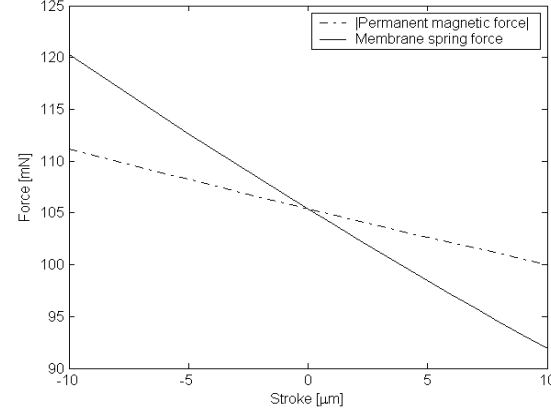

Figure 6.4: The permanent magnetic force and the spring force as function of the stroke around the equilibrium position.

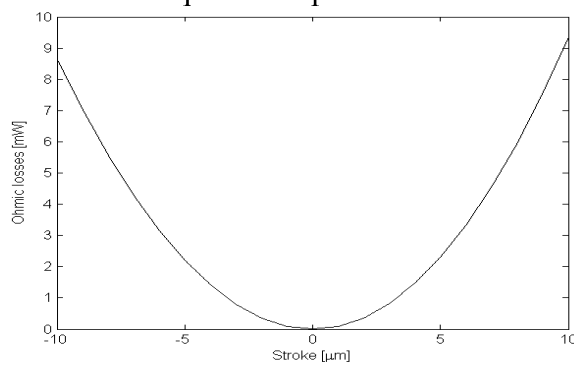

Figure 6.7: The Ohmic losses as function of the actuator stroke. (Total coil area; $0.6 \mathrm{~mm}^{2}$ )

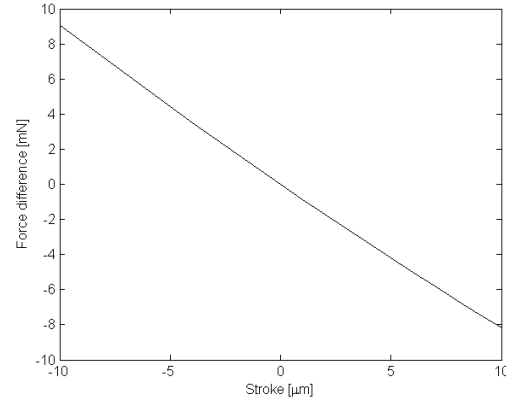

Figure 6.5: The force difference between the two characteristics, as function of the actuator stroke.

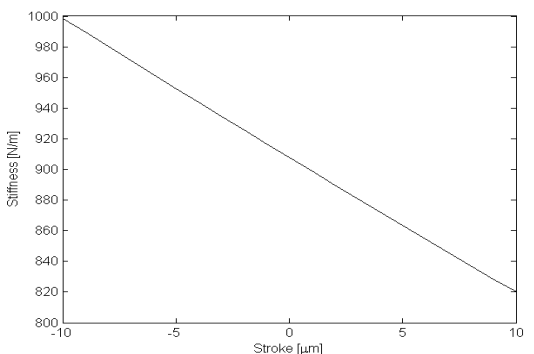

Figure 6.8: The resulting actuator stiffness as function of the actuator sroke. 


\section{REALISATION AND TESTING}

As a first step in the realization of the actuators, the suspension is manufactured and its non-linear stiffness is measured. A measurement setup is designed $^{3}$ and built to measure both the non-linear stiffness of the suspension and the (dynamic) behaviour of the total actuator. Figure 7.1 shows the schematic lay-out the measurement device. The test setup consists of two sensors placed on a parallel guiding mechanism, both connected with a lever to a micro spindle. The piëzo electric force

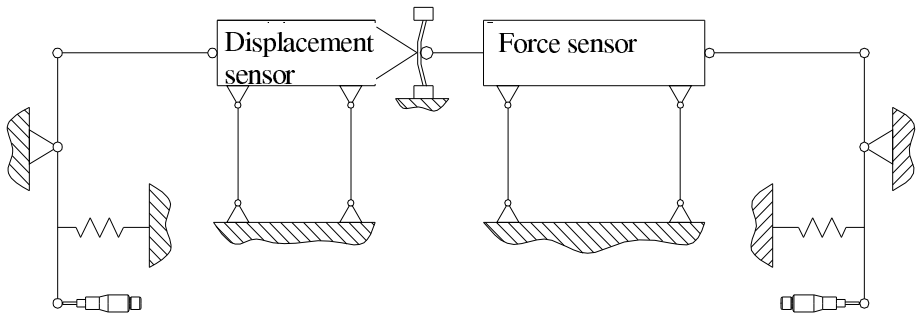

Figure 7.1: Schematic layout of the measurement device. sensor $^{7}$ is translated by means of a micro spindle and a lever. This sensor is connected to the membrane suspension by means of a rod, thereby only transferring the axial displacement. The translation is measured by an optical displacement sensor $^{8}$. Force can thus be measured as function of the displacement. The parallel guiding mechanism for this sensor is needed for calibration. The sensors are placed concentrically with the suspension. The suspension is placed in a container $(\varnothing 25 \times 8 \mathrm{~mm})$ to be more handy. Figure 7.2 shows the design in detail. The design consists of two monolithic blocks, each containing an elastic guiding mechanism. The container with the membrane is placed between the two blocks.
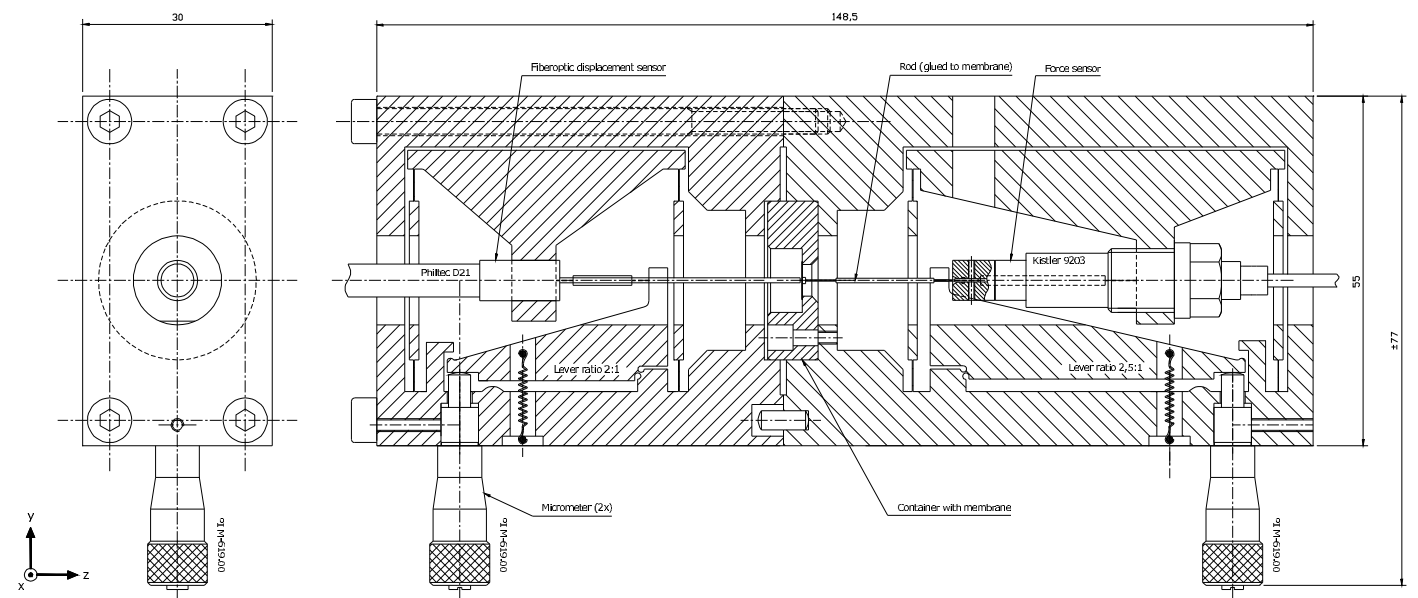

Figure 7.2: Detailed drawing of the measurement set-up.

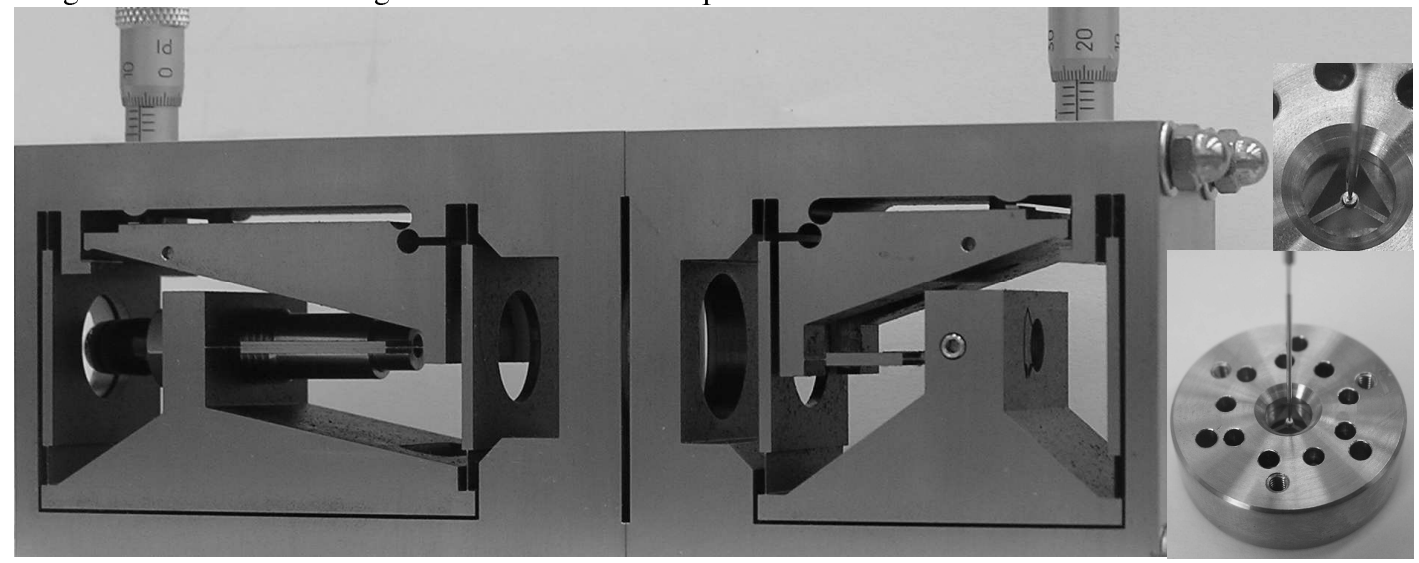

Figure 7.3: Photo of the manufactured test setup. The photo in the lower right corner shows a container with a suspension. The stiffened rod that is the connection between the force sensor and the membrane suspension is clearly visible. 
Different suspensions were tested and compared with the non linear finite element calculations made in Ailgor. Fizure 7.4 shows the measurement results of two identical membranes. The membranes are made of a $30 \mu \mathrm{m}$ thick titanium foil and have leaf springs of $0.35 \mathrm{~mm}$ width. The membrane is clamped at their outer edge in the container and subjected to an outof-plane movement of about $\pm 100 \mu \mathrm{m}$. During this movement the forces were measured. A few remarks can be made:

- Around its central position a negative stiffness is observed. This can be explained, partly from the present tensions in the material from the production process of the foil, and partly from the clamping in the container. However the actuator will not be used around this position; the permanent magnet provides the membrane with a much larger static deflection. The translation needed to deform the mirror is a small movement around this static deflection.

- $\quad$ In the regime of $75 \pm 10 \mu \mathrm{m}$ (figure 6.3 and 6.4), the measured membranes show a higher stiffness than the FEM predictions.
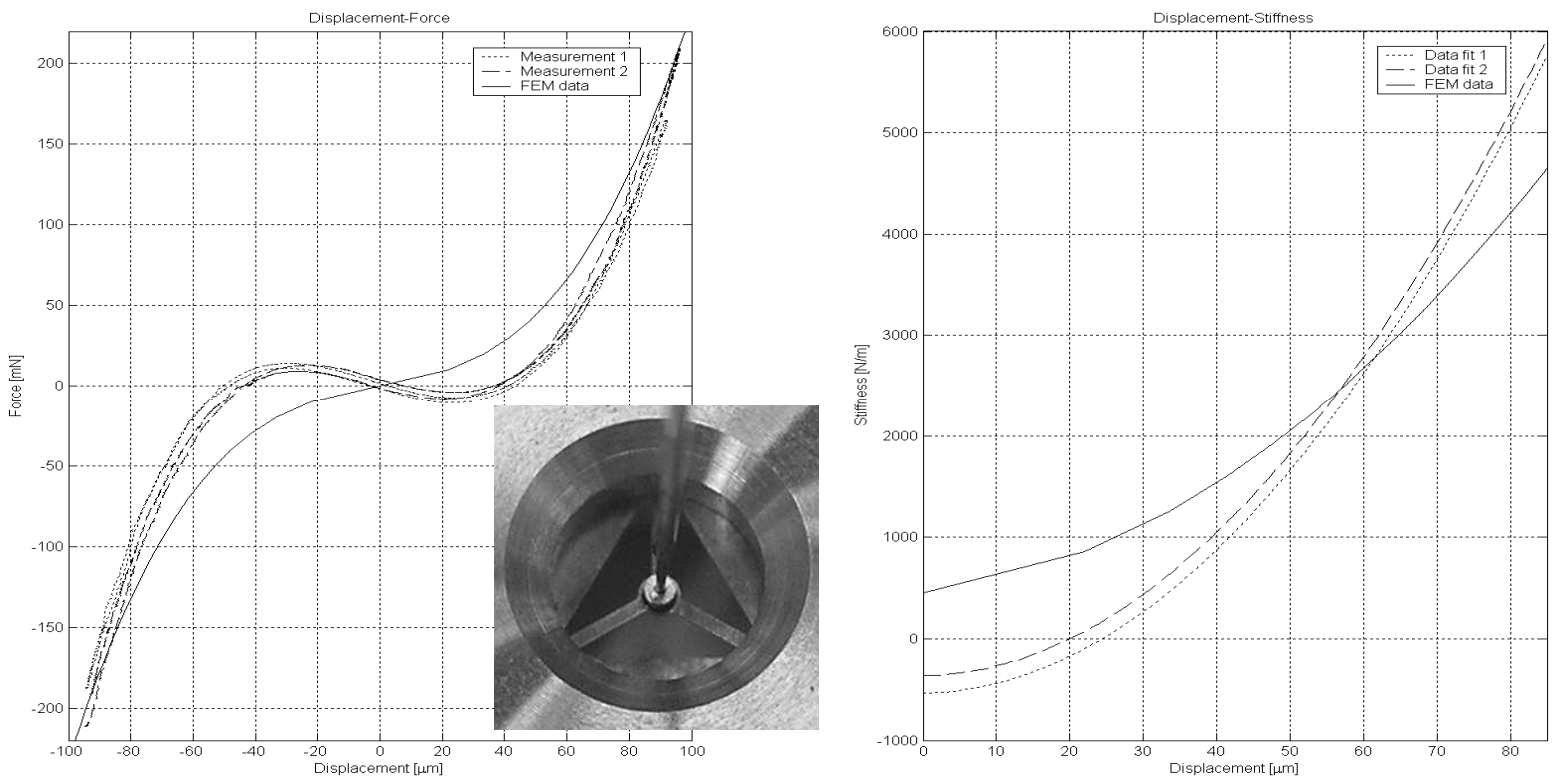

Figure 7.4: Comparison of the non-linear spring characteristic as measured in the test set-up and predicted by FEM calculations.

\subsection{The first actuator prototypes}

With the knowledge gained from the measurements the new actuator can be put together. Figure 7.5 shows the different parts of the actuator. Currently, the actuator is being tested in the test set-up. The actuator is placed in a container in front of the displacement sensor, replacing the part with the force sensor.

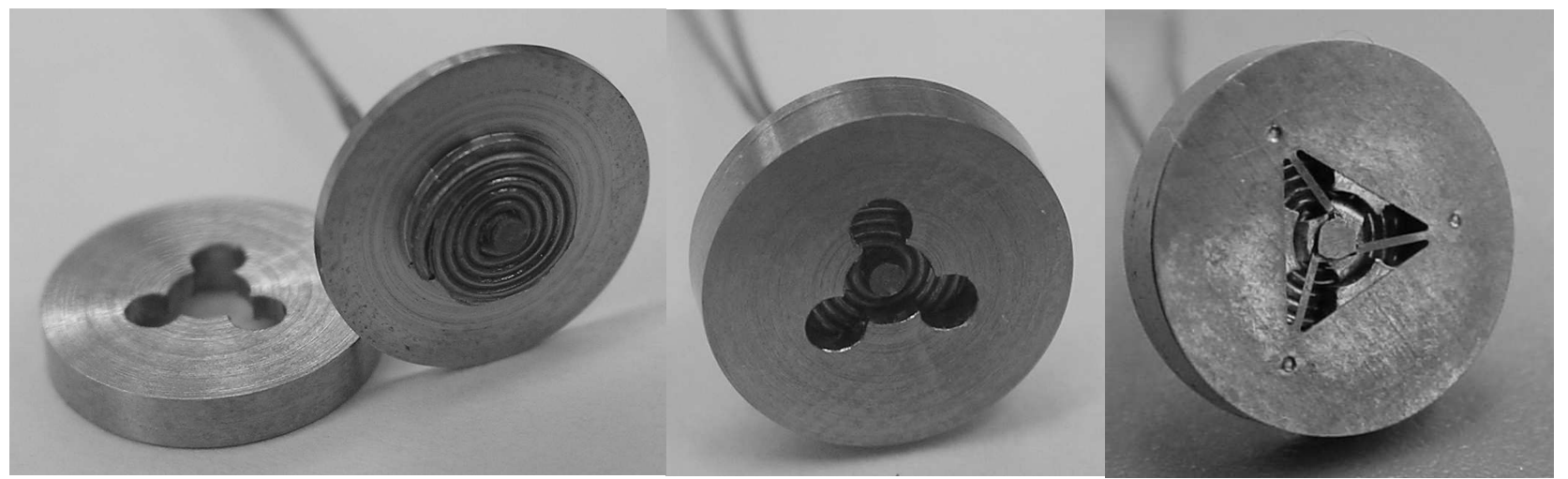

Figure 7.5: The different parts of the actuator. On the right the first assembled actuator is shown. 


\section{THE ACTUATOR GRID}

The actuator as presented is designed to be easily producible in an array. Figure 8.1 shows how the base plate for a 61 actuator array is made. This base plate will be covered by the $30 \mu \mathrm{m}$ thick titanium foil, forming the suspension for the ferromagnetic cores. From the backside, subassemblies with the coils and permanent magnets can be plugged in.

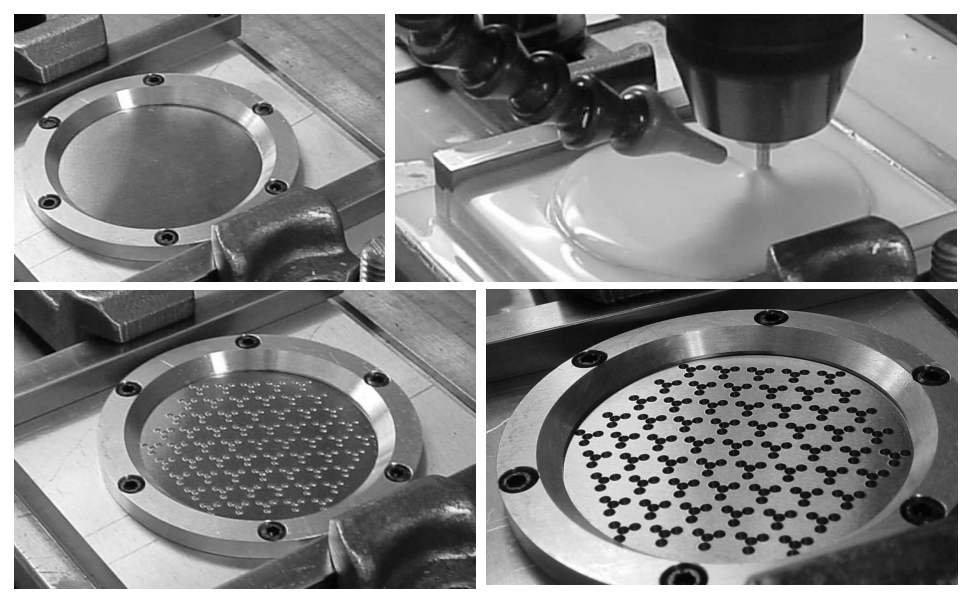

Figure 8.1: Manufacturing of the base plate for the 61 actuator array (top left). The finished actuator array (top right). Details of the front and backside of the base plate (lower right).

The array as presented serves as a standard building block for very large actuator arrays. The actuator grid is therefore perfectly extendable. It is possible to put the actuators in every desirable grid; hexagonal, orthogonal or polar.
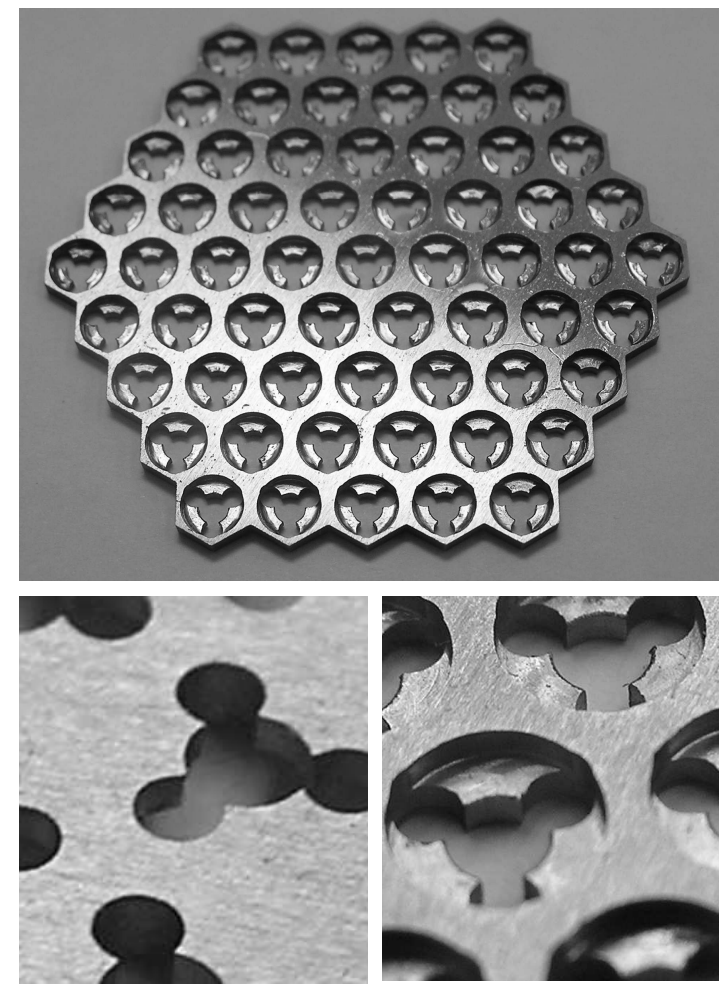

\section{SUPPORT STRUCTURE}

The actuator plate together with the reflective deformable membrane and connection layer forms a thin plate of only a few $\mathrm{mm}$ with limited out-of-plane stiffness. To add extra stiffness, the height of the construction can be increased. The energy dissipation in the actuator plate will lead to an axial temperature gradient, which leads to deformation. To correct for this deformation, the actuators will need a larger stroke. This additional stroke is unwanted because it will lead to an increase in energy dissipation, which again leads to more deformation. Furthermore it is desirable that with the extra stiffness limited mass is added. This means that a light weighted and stiff construction is needed, for example a honeycomb structure. This structure has the disadvantage that the thermal conductivity is bad in comparison to that of a solid, leading to unacceptably large deformations. The desired construction should be light and stiff and provide a mechanically stable thermally insensitive reference.

This connection can be achieved by connecting the individual standard building blocks with three hinged leafsprings, placed under $120^{\circ}$, to a light weight stiff honeycomb structure. For optimally addressing of the stiffness of the support structure, the hinged leafsprings should be connected on the intersections of the walls of the honeycomb core.

Difference in expansion between actuator plate and honeycomb structure, introduced by different materials with different coefficient of thermal expansion or by a difference in temperature as a consequence of the energy dissipation in the actuators, will not lead to unwanted deformation. With the in-plane expansion the support structure remains flat. 
Additional advantage is that the energy dissipated in heat the actuators will be transported by means of natural convection in the air layer between actuator plate and honeycomb structure. The honeycomb structure is made of thin aluminum plate, so a short thermal time constant is present, quick adaptation to changes in environmental temperature is possible.

\section{CONCLUSION}

A new adaptive deformable mirror is being developed. The design consists of a thin membrane which acts as the correcting element. A grid of low voltage electro-magnetical push-pull actuators, impose out-of-plane displacements on the mirror's membrane. To provide a stable and stiff reference plane for the actuators, a mechanically stable and thermally decoupled honeycomb support structure is added.

One of the most challenging parts in this design is the actuator grid. This actuator grid consists of an array of variable reluctance actuators. The actuator consists of a closed magnetic circuit in which a strong permanent magnet provides a static magnetic force attracting ferromagnetic material. By applying a current through the coil which is situated around this magnet, this force can be influenced. In the design a match is made between a negative stiffness of the magnet and a positive stiffness of the membrane suspension.

The actuator is both mechanically and electromagnetically analysed. Through this analysis, insight is gained on how important parameters such as mechanical actuator stiffness and power dissipation can be determined by the design.

The first actuators have been built, together with parts of a 61-actuator array. The power dissipation in the actuator grid is in the order of milliwatts per actuator. Because of this low power dissipation active cooling is not required.

A measurement setup is designed and built to measure both the stiffness of the membrane suspension as well as the (dynamic) behaviour of the actuator.

The actuator is designed to be easily producible in an array. Such an array serves as a standard building block for very large actuator arrays. The actuator grid is therefore perfectly extendable. It is possible to put the actuators in every desirable grid; hexagonal, orthogonal or polar.

\section{ACKNOWLEDGEMENTS}

The work done is supported by the Dutch Innovative Research Project (IOP) Precision Technology

\section{REFERENCES}

1. R. Hamelinck, N. Rosielle, P. Kappelhof, B. Snijders, M. Steinbuch, "Large adaptive deformable membrane mirror with high actuator density", SPIE Proc. Vol. 5490, pp. 1482-1492, 2004

2. R.F.M.M. Hamelinck, Design of a new adaptive deformable mirror, Technische Universiteit Eindhoven, Eindhoven, 2003, PE 2003-108 (in Dutch)

3. E.J.A. Manders, Design of a device to measure the out-of-plane, nonlinear stiffness of circular membranes, Technische Universiteit Eindhoven, Eindhoven, 2004

4. P.C.J.N. Rosielle, E.A.G. Reker, Design Principles 1, Lecture note 4007, Technische Universiteit Eindhoven, 1999 (in Dutch)

5. Stephen P. Timoshenko, S. Woinowsky-Krieger, "Theory of plates and shells", $2^{\text {nd }}$ ed, McGraw-Hill, London, 1970

6. G. Brusa, A. Riccardi, M. Accardo, V. Biliotti, M. Carbillet, C. del Vecchio, S. Esposito, B. Femenía, O. Feeney, L. Fini, S. Gennari, L. Miglietta, P. Salinari and P. Stefanini, "From adaptive secondary mirrors to extra-thin extra-large adaptive primary mirrors", Backaskog workshop on extremely large telescopes, vol. 57 ESO Proc. pp. 181-201, Lund Obs. and ESO, 1999

7. Homepage Kistler instruments, http://www.kistler.com

8. Homepage Philtec sensors, http://www.philtec.com

9. www.algor.com

10. www.ansoft.com 